\title{
Alterações da microbiota conjuntival e palpebral após uso tópico de lomefloxacina e tobramicina na cirurgia de catarata e cirurgia refrativa
}

\author{
Changes in conjunctival and lid flora after topical use of lomefloxacin and tobramycin \\ in cataractand refractivesurgery
}

\author{
Ana Luisa Höfling - Lima ${ }^{1}$ \\ Michel Eid Farah² \\ Luciano Montenegros ${ }^{3}$ \\ Lênio Souza Alvareng'a ${ }^{4}$ \\ Maria Regina Catai Chalita ${ }^{4}$ \\ Maria Cecília Zorat You ${ }^{5}$
}

\begin{tabular}{l} 
RESUMO \\
\hline Objetivo: Avaliar as alterações da microbiota conjuntival e palpebral \\
após o uso tópico de colírios de lomefloxacina ou tobramicina a $0,3 \%$ \\
no preparo de pacientes a serem submetidos à cirurgia de catarata e \\
cirurgia refrativa e avaliar a sensibilidade das bactérias isoladas da \\
conjuntiva e pálpebra a estes antibióticos. Métodos: Realizou-se um \\
estudo prospectivo de análise da microbiota conjuntival e palpebral de \\
pacientes submetidos à cirurgia de catarata e cirurgia refrativa (PRK ou \\
LASIK). O estudo da microbiota conjuntival e palpebral foi realizado \\
antes das cirurgias, sem uso de agentes para profilaxia, no período pós- \\
operatório durante o uso de profilaxia, e após a suspensão dos antibió- \\
ticos. Resultados: O uso tópico de tobramicina e lomefloxacina reduziu \\
o número de colheitas positivas na conjuntiva e pálpebra nos indiví- \\
duos submetidos à cirurgia de catarata e cirurgia refrativa. Em ambos \\
os grupos de pacientes ocorreu maior resistência dos microrganismos \\
à tobramicina. No grupo submetido à cirurgia de catarata, pacientes \\
tratados profilaticamente com tobramicina tiveram uma recuperação da \\
microbiota mais lenta após a suspensão do antibiótico do que com a \\
lomefloxacina, ocorrendo o oposto no grupo submetido à cirurgia \\
refrativa. Conclusão: Tanto a lomefloxacina quanto a tobramicina foram \\
eficazes em diminuir o número de culturas positivas da conjuntiva e da \\
pálpebra enquanto estavam sendo administrados, sendo esta diminui- \\
ção mais acentuada na conjuntiva. Houve maior resistência à tobramicina \\
na maioria das colheitas realizadas. A lomefloxacina apresentou núme- \\
ro menor de bactérias resistentes do que a tobramicina durante o uso \\
da antibioticoterapia tópica profilática. O uso de antibiótico reduziu o \\
número de amostras positivas.
\end{tabular}

Descritores: Infecções oculares bacterianas/microbiologia; Infecções oculares bacterianas/ prevenção \& controle; Complicações pós-operatórias/prevenção \& controle; Testes de sensibilidade microbiana; Resistência microbiana a drogas; Soluções oftálmicas; Quinolonas/ uso terapêutico; Tobramicina/uso terapêutico; Quinolonas/administração e dosagem; Tobramicina/administração \& dosagem; Estudo comparativo; Estudos prospectivos

\section{INTRODUÇ̃̃̃O}

Dentre os procedimentos cirúrgicos mais realizados pelos oftalmologistas na atualidade estão a cirurgia de catarata e a cirurgia para correção de ametropias. São procedimentos relativamente seguros e com baixa incidên- 
cia de complicações, considerando-se o grande número de cirurgias realizadas. Apesar da incidência baixa, as complicações per-operatórias, quando ocorrem, podem afetar a reabilitação visual de um número significativo de pacientes ${ }^{(1)}$.

As complicações podem ser divididas em per-operatórias e pós-operatórias, sendo o pós-operatório onde podemos observar as infecções intra-oculares, que podem após um procedimento ocular simples, levar à perda visual irrecuperável.

Vários estudos evidenciam que a maioria dos microrganismos que causam infecções após cirurgia ocular faz parte da microbiota normal da conjuntiva e da pálpebra do próprio indivíduo $^{(1)}$. A maior freqüência de isolamentos positivos está relacionada aos Staphylococcus coagulase negativas (SCN) e destes, o Staphylococcus epidermidis ${ }^{(2)}$. Para que a infecção intra-ocular ocorra, uma quantidade suficiente de microrganismos precisa penetrar no olho, de modo que não possa ser eliminada pelos mecanismos de defesa normais do indivíduo. Vários estudos analisam a eficácia da antibioticoterapia tópica no preparo do paciente para cirurgias oftalmológicas, comprovando que a utilização de antibiótico tópico antes e após a cirurgia é eficaz na redução e, às vezes, na eliminação da microbiota da conjuntiva ${ }^{(3)}$, podendo desta forma diminuir a incidência de infecção.

Vários fatores devem ser levados em conta na escolha do antibiótico a ser utilizado com fins profiláticos no pré e pósoperatório, como a sensibilidade normal da microbiota, dose necessária, toxicidade, freqüência de utilização e custo do tratamento. Vários antibióticos podem ser utilizados como os aminoglicosídeos e as quinolonas.

A lomefloxacina é uma quinolona difluorinada de amplo espectro, com ação contra bactérias Gram-positivas e Gramnegativas ${ }^{(4)}$. Ela inibe a enzima bacteriana DNA-girase, com conseqüente inibição da síntese de DNA bacteriano ${ }^{(5)}$. Possui rápido efeito bactericida aumentando em uma ou duas vezes os valores da concentração inibitória mínima (MIC), facilita a atividade antimicrobiana da reação imuno celular já em subníveis da MIC e seu efeito pós-antibiótico suporta sua potente atividade ${ }^{(6-7)}$. Em oftalmologia é utilizada na forma de colírio a $0,3 \%$, permanecendo no filme lacrimal e em alguns tecidos oculares por muitas horas acima do valor MIC $_{90}$.

A tobramicina faz parte do grupo dos aminoglicosídeos, sendo também um dos principais antibióticos usados para o tratamento de infecções oculares. Age pela ligação ao ribossomo das bactérias, inibindo a síntese protéica. Os aminoglicosídeos são, em geral, bacteriostáticos, porém em altas doses, podem ter efeito bactericida. São potentes contra microrganismos Gram-negativos (Pseudomonas sp, Proteus sp, Klebsiella sp, Escherichia coli, Salmonella sp, Serratia sp, Haemophylus $s p$, etc.) e têm sensibilidade intermediária a outras bactérias Gram-positivas como Staphylococcus coagulase negativa (SCN) e Staphylococcus aureus ${ }^{(8-9)}$.

\section{OBJETIVO}

O objetivo deste estudo é avaliar a flora conjuntival e palpebral após o uso tópico de colírio de lomefloxacina e tobramicina $0,3 \%$ no preparo de pacientes a serem submetidos à cirurgia de catarata e cirurgia refrativa e avaliar a sensibilidade das bactérias isoladas da conjuntiva e pálpebra a estes antibióticos.

\section{MÉTODOS}

Realizamos um estudo prospectivo de análise da microbiota conjuntival e palpebral de um grupo de 60 pacientes (120 olhos) que foram submetidos à cirurgia de catarata e de outro grupo de 60 pacientes (120 olhos) que foram submetidos à cirurgia refrativa (PRK ou LASIK). O grupo submetido à cirurgia de catarata era composto de 40 mulheres $(66,6 \%)$ e 20 homens $(33,3 \%)$ e a idade variou de 12 a 92 anos, com mediana da idade 69,5 anos. O grupo submetido à cirurgia refrativa era composto de 31 mulheres $(51,6 \%)$ e 29 homens $(48,3 \%)$ e a idade variou de 22 a 50 anos,com mediana da idade 31,5 anos. Cada paciente foi submetido à cirurgia oftalmológica em apenas um olho, servindo a análise laboratorial do olho não operado como grupo controle. Todas as cirurgias foram realizadas pelo mesmo cirurgião e as orientações e cuidados pré e pósoperatórios foram dados pela mesma pessoa.

No grupo dos pacientes submetidos à cirurgia de catarata, cada olho foi submetido à cultura de conjuntiva e pálpebra em cinco visitas: uma antes do início da profilaxia (pré); uma imediatamente antes da cirurgia, já tendo usado a profilaxia com um dos antibióticos estudados por 3 dias (imediatamente pré); 3 dias após a cirurgia usando a profilaxia tópica (3 dias); com duas semanas após a cirurgia ainda em uso da profilaxia (2 semanas); com 1 mês após a cirurgia, sem a utilização de antibióticos por 15 dias (1 mês).

No grupo de pacientes submetidos à cirurgia refrativa, cada olho foi submetido à cultura conjuntival e palpebral em três visitas: uma antes do início da profilaxia (pré); 1 semana após a cirurgia usando a profilaxia tópica (1 sem); 1 mês após a cirurgia, sem a utilização de antibióticos há 15 dias (1 mês).

Analisamos a ação de dois antibióticos: 30 pacientes de cada grupo receberam como antibiótico profilático colírio de lomefloxacina a $0,3 \%$ usado 4 vezes ao dia e os outros 30 pacientes receberam como antibiótico profilático colírio de tobramicina a $0,3 \%, 4$ vezes ao dia.

A decisão do antibiótico a ser introduzido na profilaxia foi de forma alternada até completar o número preconizado na amostra. Só poderia continuar no estudo o indivíduo com cultura positiva no qual o microrganismo isolado fosse sensível à profilaxia preconizada. Todos os pacientes foram previamente submetidos ao exame oftalmológico completo, não sendo constatada nenhuma alteração ocular, como alergia ou alterações de superfície cornea- 
na. Ficou estabelecido que se houvesse qualquer sinal ou suspeita de toxicidade às drogas usadas, estes indivíduos seriam imediatamente excluídos do estudo.

O material colhido da conjuntiva e pálpebra de cada olho foi encaminhado para análise laboratorial, que consistia de cultura, identificação de microrganismos e testes de sensibilidade antimicrobiana. Todas as amostras colhidas para cultura foram semeadas em meio sólido (Ágar sangue) e líquido (BHI). Considerou-se positivo, o crescimento de microrganismos em qualquer um dos meios inoculados. Quando o microrganismo identificado no meio sólido e líquido foi diferente, considerouse o resultado positivo para cada amostra e as duas cepas foram identificadas e submetidas aos testes de susceptibilidade antimicrobiana.

Os microrganismos isolados foram submetidos ao teste de sensibilidade de difusão em discos ${ }^{(10)}$, com a concentração do antibiótico no disco de $10 \mathrm{mg}$ para as duas drogas testadas ${ }^{(11)}$. A leitura foi feita medindo-se o diâmetro do halo de inibição ao redor do disco e, de acordo com o critério do "National Committee for Clinical Laboratory Standards"(NCCLS, Washington, DC) o microrganismo foi considerado resistente ao antibiótico se o halo fosse $=12 \mathrm{~mm}$, intermediário de 13 até $14 \mathrm{~mm}$ e susceptível $=15 \mathrm{~mm}^{(11)}$.

Quanto à análise estatística dos dados, verificamos as porcentagens de culturas positivas em cada grupo, bem como as porcentagens de redução desta positividade com o uso da profilaxia. A análise da diferença na proporção entre os períodos e os resultados pré-profilaxia, bem como a diferença entre os diversos grupos foi verificada pelo teste de proporção pela curva de Gauss (teste z). Nas tabelas de associação, utilizouse o teste do Qui quadrado $\left(\mathrm{X}^{2}\right)$ para duas amostras independentes. Quando presentes as restrições de Cochran, utilizouse o teste exato de Fisher. O nível de rejeição para a hipótese de nulidade foi fixado sempre em um valor menor ou igual a 0,05 (5\%). Quando a estatística calculada apresentou significância, usamos um asterisco para caracterizá-la.

\section{RESULTADOS}

Na análise do grupo submetido à cirurgia de catarata, verificou-se crescimento positivo da microbiota conjuntival em $75 \%$ das amostras estudadas de ambos os olhos no período pré-operatório, antes da introdução da profilaxia. As amostras das pálpebras analisadas apresentaram crescimento positivo em 98,3\%. O melhor efeito do antibiótico tópico foi observado 2 semanas após a cirurgia, sendo que estes pacientes apresentaram na conjuntiva apenas $13,3 \%$ de culturas positivas e na pálpebra 43,3\%. Após a interrupção da profilaxia por 15 dias, 1 mês após a cirurgia, notamos que as porcentagens de

\begin{tabular}{|c|c|c|c|c|c|}
\hline & \multirow{2}{*}{$\begin{array}{l}\text { Sem profilaxia } \\
3 \text { dias antes } \\
\text { da cirurgia }\end{array}$} & \multicolumn{3}{|c|}{ Com profilaxia } & \multirow{2}{*}{$\begin{array}{c}\text { Após profilaxia } \\
15 \text { dias } \\
\text { sem antibiótico }\end{array}$} \\
\hline & & $\begin{array}{l}\text { No centro } \\
\text { cirúrgico }\end{array}$ & $\begin{array}{c}3 \text { dias } \\
\text { após cirurgia }\end{array}$ & $\begin{array}{c}2 \text { semanas } \\
\text { após cirurgia }\end{array}$ & \\
\hline \multicolumn{6}{|l|}{ Conjuntiva } \\
\hline$\%$ do total & 75,0 & 21,7 & 15,0 & 13,3 & 33,3 \\
\hline \% de redução & & 71,1 & 80,0 & 82,2 & 55,6 \\
\hline \multicolumn{6}{|l|}{ Pálpebra } \\
\hline$\%$ do total & 98,3 & 65,0 & 43,3 & 43,3 & 70,0 \\
\hline \% de redução & & 33,9 & 55,9 & 55,9 & 28,8 \\
\hline
\end{tabular}

\begin{tabular}{|c|c|c|c|c|c|}
\hline & \multirow{2}{*}{$\begin{array}{c}\text { Sem profilaxia } \\
3 \text { dias antes } \\
\text { da cirurgia }\end{array}$} & \multicolumn{3}{|c|}{ Com profilaxia } & \multirow{2}{*}{$\begin{array}{c}\text { Após profilaxia } \\
15 \text { dias } \\
\text { sem antibiótico }\end{array}$} \\
\hline & & $\begin{array}{l}\text { No centro } \\
\text { cirúrgico }\end{array}$ & $\begin{array}{c}3 \text { dias } \\
\text { após cirurgia }\end{array}$ & $\begin{array}{l}2 \text { semanas } \\
\text { após cirurgia }\end{array}$ & \\
\hline \multicolumn{6}{|l|}{ Conjuntiva } \\
\hline$\%$ do total & 70,0 & 23,3 & 16,7 & 10,0 & 40,0 \\
\hline \% de redução & & 66,7 & 76,2 & 85,7 & 42,9 \\
\hline z calc & & $3,10^{*}$ & $4,56^{\star}$ & $6,00^{*}$ & $2,77^{*}$ \\
\hline \multicolumn{6}{|l|}{ Pálpebra } \\
\hline$\%$ do total & 100,0 & 66,7 & 46,7 & 40,0 & 73,3 \\
\hline \% de redução & & 33,3 & 53,3 & 60,0 & 26,7 \\
\hline z calc & & $2,29^{*}$ & $4,58^{*}$ & $4,29^{*}$ & $2,68^{*}$ \\
\hline
\end{tabular}


culturas positivas voltam a aumentar, ficando em $33,3 \%$ na conjuntiva e $70 \%$ na pálpebra (Tabela 1).

Esta análise foi feita também para cada antibiótico usado e, com relação à lomefloxacina notamos uma porcentagem de redução de culturas conjuntivais e palpebrais positivas de $85,7 \%$ e $60 \%$, respectivamente (Tabela 2). Analisando o grupo que recebeu tobramicina como profilaxia tópica, verificamos uma porcentagem de redução de culturas positivas de $79,2 \%$ e $51,7 \%$ para conjuntiva e pálpebra, respectivamente (Tabela 3 ).

As diferenças apresentadas na positividade das amostras de conjuntiva e nas de pálpebra quando receberam profilaxia foram estatisticamente significantes tanto para a profilaxia com tobramicina quanto com lomefloxacina (Tabelas 2 e 3 ).

O uso de lomefloxacina tópica levou à máxima redução de culturas positivas na conjuntiva e pálpebra na segunda semana após a cirurgia, enquanto com o uso da tobramicina a máxima redução foi observada no terceiro dia de pós-operatório (Tabela 4). Comparando-se a redução de culturas positivas com uma e outra profilaxia observou-se que os pacientes tratados com tobramicina apresentaram $66,7 \%$ de redução e os que receberam lomefloxacina $42,9 \%$ na colheita de um mês, já com quinze dias sem antibiótico. Este achado revela que nos casos tratados profilaticamente com tobramicina depois da suspensão do antibiótico houve uma recuperação da microbiota significantemente mais lenta.

O Staphylococcus coagulase negativa ( $\mathrm{SCN}$ ) foi o microrganismo mais freqüentemente isolado tanto na conjuntiva como na pálpebra. Apenas para esta bactéria, fizemos a mesma análise da porcentagem de redução da profilaxia com o uso dos dois antibióticos e nota-se que os resultados são semelhantes à análise do grupo geral de microrganismos (Tabelas 5, 6 e 7).

Analisando a sensibilidade dos microrganismos isolados no grupo submetido à cirurgia de catarata verificamos que, em praticamente todos os períodos estudados, ocorre uma maior resistência dos microrganismos à tobramicina (Tabela 8).

No grupo submetido à cirurgia refrativa também observamos uma maior resistência dos microrganismos à tobramicina. No período pré-operatório na conjuntiva e pálpebra e com uma semana de tratamento a diferença observada na análise da pálpebra permaneceu estatisticamente significante (Tabela 8-A).

$\mathrm{Na}$ avaliação do grupo submetido à cirurgia refrativa verificamos que houve um crescimento positivo da microbiota conjuntival no pré-operatório de $45 \%$, e um crescimento na pálpebra de $83,3 \%$. Com uma semana após a cirurgia, usando o antibiótico profilático, as porcentagens caem para $5 \%$ nas culturas conjuntivais e $41,7 \%$ nas culturas palpebrais. Podemos notar que no pós-operatório de 1 mês, onde a colheita foi

\begin{tabular}{|c|c|c|c|c|c|}
\hline & \multirow{2}{*}{$\begin{array}{c}\text { Sem profilaxia } \\
3 \text { dias antes da } \\
\text { cirurgia }\end{array}$} & \multicolumn{3}{|c|}{ Com profilaxia } & \multirow{2}{*}{$\begin{array}{c}\text { Após profilaxia } \\
15 \text { dias } \\
\text { sem antibiótico }\end{array}$} \\
\hline & & $\begin{array}{l}\text { No centro } \\
\text { cirúrgico }\end{array}$ & $\begin{array}{c}3 \text { dias } \\
\text { após cirurgia }\end{array}$ & $\begin{array}{c}2 \text { semanas } \\
\text { após cirurgia }\end{array}$ & \\
\hline \multicolumn{6}{|l|}{ Conjuntiva } \\
\hline$\%$ do total & 80,0 & 20,0 & 13,3 & 16,7 & 26,7 \\
\hline \% de redução & & 75,0 & 83,3 & 79,2 & 66,7 \\
\hline z calc & & $4,13^{*}$ & $5,89^{\star}$ & $2,64^{*}$ & $3,73^{*}$ \\
\hline \multicolumn{6}{|l|}{ Pálpebra } \\
\hline$\%$ do total & 96,7 & 63,3 & 40,0 & 46,7 & 66,7 \\
\hline \% de redução & & 34,5 & 58,6 & 51,7 & 31,0 \\
\hline z calc & & $2,17^{*}$ & $3,46^{*}$ & $3,63^{*}$ & $2,29^{*}$ \\
\hline
\end{tabular}

\begin{tabular}{|c|c|c|c|c|}
\hline & \multicolumn{3}{|c|}{ Com profilaxia } & \multirow{2}{*}{$\begin{array}{c}\text { Após profilaxia } \\
15 \text { dias sem antibiótico }\end{array}$} \\
\hline & No centro cirúrgico & 3 dias após cirurgia & 2 semana após cirurgia & \\
\hline \multicolumn{5}{|l|}{ Conjuntiva } \\
\hline Lomefloxacina & 66,7 & 76,2 & 85,7 & 42,9 \\
\hline Tobramicina & 75,0 & 83,3 & 79,2 & 66,7 \\
\hline z calc & 0,73 & 0,70 & 0,65 & $2,09^{*}$ \\
\hline \multicolumn{5}{|l|}{ Pálpebra } \\
\hline Lomefloxacina & 33,3 & 53,3 & 60,0 & 26,7 \\
\hline Tobramicina & 34,5 & 58,6 & 51,7 & 31,0 \\
\hline z calc & 0,09 & 0,42 & 0,62 & 0,39 \\
\hline
\end{tabular}




\begin{tabular}{|c|c|c|c|c|c|}
\hline & \multirow{2}{*}{$\begin{array}{c}\text { Sem profilaxia } \\
3 \text { dias } \\
\text { antes da cirurgia }\end{array}$} & \multicolumn{3}{|c|}{ Com profilaxia } & \multirow{2}{*}{$\begin{array}{c}\text { Após profilaxia } \\
15 \text { dias } \\
\text { sem antibiótico }\end{array}$} \\
\hline & & $\begin{array}{l}\text { No centro } \\
\text { cirúrgico }\end{array}$ & $\begin{array}{c}3 \text { dias } \\
\text { após cirurgia }\end{array}$ & $\begin{array}{l}2 \text { semanas } \\
\text { após cirurgia }\end{array}$ & \\
\hline \multicolumn{6}{|l|}{ Conjuntiva } \\
\hline$\%$ do total & 53,3 & 23,3 & 13,3 & 6,7 & 26,7 \\
\hline \% de redução & & 56,3 & 75,0 & 87,5 & 50,0 \\
\hline z calc & & $2,23^{*}$ & $1,88^{*}$ & $4,25^{\star}$ & $2,19^{*}$ \\
\hline \multicolumn{6}{|l|}{ Pálpebra } \\
\hline$\%$ do total & 93,3 & 63,3 & 43,3 & 33,3 & 56,7 \\
\hline \% de redução & & 32,1 & 53,6 & 64,3 & 39,3 \\
\hline z calc & & $2,17^{*}$ & $3,53^{*}$ & $3,39^{*}$ & $2,36^{*}$ \\
\hline
\end{tabular}

Tabela 6. Porcentagem de culturas e porcentagem de redução das culturas com isolamento de Staphylococcus coagulase negativa em olhos $(n=30)$ submetidos à facectomia, tratados profilaticamente com Tobramicina tópica, de acordo com presença ou não de profilaxia concomitante e o local da colheita (conjuntiva ou pálpebra) e resultados da estatística, São Paulo, 2000

\begin{tabular}{|c|c|c|c|c|c|}
\hline & \multirow{2}{*}{$\begin{array}{c}\text { Sem profilaxia } \\
3 \text { dias } \\
\text { antes da cirurgia }\end{array}$} & \multicolumn{3}{|c|}{ Com profilaxia } & \multirow{2}{*}{$\begin{array}{c}\text { Após profilaxia } \\
15 \text { dias } \\
\text { sem antibiótico }\end{array}$} \\
\hline & & $\begin{array}{l}\text { No centro } \\
\text { cirúrgico }\end{array}$ & $\begin{array}{c}3 \text { dias } \\
\text { após cirurgia }\end{array}$ & $\begin{array}{l}2 \text { semanas } \\
\text { após cirurgia }\end{array}$ & \\
\hline \multicolumn{6}{|l|}{ Conjuntiva } \\
\hline$\%$ do total & 50,0 & 16,7 & 13,3 & 13,3 & 23,3 \\
\hline \% de redução & & 66,6 & 73,3 & 73,3 & 53,3 \\
\hline z calc & & $3,53^{*}$ & $4,29^{*}$ & $2,17^{*}$ & $2,23^{*}$ \\
\hline \multicolumn{6}{|l|}{ Pálpebra } \\
\hline$\%$ do total & 86,7 & 60,0 & 33,3 & 40,0 & 60,0 \\
\hline \% de redução & & 30,8 & 61,5 & 53,8 & 30,8 \\
\hline z calc & & 1,73 & $3,75^{\star}$ & $3,46^{*}$ & 1,73 \\
\hline
\end{tabular}

Tabela 7. Porcentagem de redução nas culturas com isolamento de Staphylococcus coagulase negativa após antibioticoterapia profilática tópica de acordo com a presença ou não de profilaxia concomitante e o local da colheita (conjuntiva ou pálpebra) e a droga utilizada, em olhos ( $n=30$ ) submetidos à facectomia e resultados da estatística, São Paulo, 2000

\begin{tabular}{|c|c|c|c|c|}
\hline & \multicolumn{3}{|c|}{ Com profilaxia } & \multirow{2}{*}{$\begin{array}{c}\text { Após profilaxia } \\
15 \text { dias sem antibióticc }\end{array}$} \\
\hline & No centro cirúrgico & 3 dias após cirurgia & 2 semanas após cirurgia & \\
\hline \multicolumn{5}{|l|}{ Conjuntiva } \\
\hline Lomefloxacina & 56,3 & 75,0 & 87,5 & 50,0 \\
\hline Tobramicina & 66,7 & 73,3 & 73,3 & 53,3 \\
\hline z calc & 0,87 & 0,15 & 1,33 & 0,26 \\
\hline \multicolumn{5}{|l|}{ Pálpebra } \\
\hline Lomefloxacina & 32,1 & 53,6 & 64,3 & 39,3 \\
\hline Tobramicina & 30,8 & 61,5 & 53,8 & 30,8 \\
\hline z calc & 0,11 & 0,65 & 0,79 & 0,65 \\
\hline
\end{tabular}

realizada estando os pacientes sem antibiótico profilático há 15 dias, as porcentagens de culturas positivas voltam a aumentar, chegando próximas aos níveis do pré-operatório (Tabela 9).

No estudo da profilaxia na cirurgia refrativa analisou-se separadamente a atuação de cada antibiótico. Nos indivíduos que receberam lomefloxacina notamos que houve uma porcentagem de redução de culturas positivas da conjuntiva de $93,3 \%$ e pálpebra de 52,2\% com 1 semana após a cirurgia (Tabela 10).

Ainda no estudo da profilaxia na cirurgia refrativa, os indivíduos que receberam tobramicina a porcentagem de redução de culturas positivas da conjuntiva e pálpebra foi de 83,3\% e 48,1\% respectivamente com 1 semana de pós-operatório (Tabela 11). As comparações das porcentagens de redução de culturas positivas com a utilização dos dois antibióticos estudados nos vários períodos não apresentam diferença significante enquanto o antibiótico tópico estava sendo administrado. Na recuperação da microbiota conjuntival, o grupo que recebeu tobramicina como profilaxia apresenta recuperação significantemente mais rápida da microbiota (Tabela 12). 


\begin{tabular}{|c|c|c|c|c|c|c|c|c|c|c|}
\hline & \multicolumn{2}{|c|}{3 dias antes da cirurgia } & \multicolumn{2}{|c|}{ No centro cirúrgico } & \multicolumn{2}{|c|}{3 Dias } & \multicolumn{2}{|c|}{2 Semanas } & \multicolumn{2}{|c|}{1 Mês } \\
\hline & Conj. & Pálp. & Conj. & Pálp. & Conj. & Pálp. & Conj. & Pálp. & Conj. & Pálp \\
\hline Lome S & 123 & 168 & 61 & 112 & 55 & 87 & 53 & 98 & 77 & 126 \\
\hline $\mathrm{R}$ & 0 & 2 & 2 & 3 & 1 & 2 & 0 & 1 & 2 & 4 \\
\hline Tobra S & 113 & 157 & 58 & 101 & 48 & 78 & 46 & 88 & 71 & 113 \\
\hline $\mathrm{R}$ & 10 & 13 & 5 & 14 & 7 & 12 & 7 & 11 & 8 & 17 \\
\hline $\begin{array}{l}\text { Estatística } \\
\text { calculada }\end{array}$ & $\begin{array}{l}X^{2} \text { calc } \\
8,443^{*}\end{array}$ & $\begin{array}{l}X^{2} \text { calc } \\
6,974^{*}\end{array}$ & $\begin{array}{c}p= \\
0,2198\end{array}$ & $\begin{array}{l}X^{2} \text { calc } \\
6,352^{*}\end{array}$ & $\begin{array}{c}p= \\
0,0303^{*}\end{array}$ & $\begin{array}{l}X^{2} \text { calc } \\
6,281^{*}\end{array}$ & $\begin{array}{c}p= \\
0,0063^{*}\end{array}$ & $\begin{array}{l}X^{2} \text { calc } \\
7,181^{*}\end{array}$ & $\begin{array}{c}X^{2} \text { calc } \\
2,669\end{array}$ & $\begin{array}{l}X^{2} \text { calc } \\
7,460^{*}\end{array}$ \\
\hline
\end{tabular}

\begin{tabular}{|c|c|c|c|c|c|c|}
\hline & \multicolumn{2}{|c|}{ Pré } & \multicolumn{2}{|c|}{1 Semana } & \multicolumn{2}{|c|}{1 Mês } \\
\hline & Conj. & Pálp. & Conj. & Pálp. & Conj. & Pálp. \\
\hline Lome S & 43 & 93 & 14 & 33 & 44 & 80 \\
\hline $\mathrm{R}$ & 0 & 0 & 0 & 0 & 1 & 1 \\
\hline Tobra S & 39 & 87 & 11 & 29 & 44 & 80 \\
\hline $\mathrm{R}$ & 4 & 7 & 3 & 4 & 1 & 1 \\
\hline $\begin{array}{l}\text { Estatística } \\
\text { calculada }\end{array}$ & $\begin{array}{c}p= \\
0,0581\end{array}$ & $\begin{array}{c}p= \\
0,0069^{*}\end{array}$ & $\begin{array}{c}p= \\
0,1111\end{array}$ & $\begin{array}{c}p= \\
0,0567\end{array}$ & $\begin{array}{c}p= \\
0,7528\end{array}$ & $\begin{array}{c}p= \\
0,7515\end{array}$ \\
\hline
\end{tabular}

Tabela 9. Porcentagem de culturas positivas e porcentagem de redução das culturas em olhos $(n=60)$ submetidos à cirurgia refrativa, tratados profilaticamente com antibioticoterapia tópica, de acordo com presença ou não de profilaxia concomitante e o local da colheita (conjuntiva ou pálpebra) e resultados da estatística,

$$
\text { São Paulo, } 2000
$$

\begin{tabular}{|lccc|} 
& $\begin{array}{c}\text { Sem profilaxia } \\
\text { 3 dias antes da } \\
\text { cirurgia }\end{array}$ & $\begin{array}{c}\text { Com profilaxia } \\
\text { 1 semana após } \\
\text { cirurgia }\end{array}$ & $\begin{array}{c}\text { Após profilaxia } \\
\text { 15 dias sem } \\
\text { antibiótico }\end{array}$ \\
$\begin{array}{l}\text { Conjuntiva } \\
\text { \% do total }\end{array}$ & 45,0 & 5,0 & 43,3 \\
\% de redução & & 88,9 & 3,7 \\
$\begin{array}{l}\text { Pálpebra } \\
\text { \% do total }\end{array}$ & 83,3 & 41,7 & 76,7 \\
$\%$ de redução & & 50,0 & 8,0 \\
\hline
\end{tabular}

$\mathrm{Na}$ análise do comportamento das culturas positivas de Staphylococcus coagulase negativa isolados nos indivíduos submetidos à cirurgia refrativa notamos a semelhança ao comportamento do total de microrganismos isolados. Observamos que o uso da lomefloxacina como profilaxia no grupo da cirurgia refrativa leva a uma porcentagem de culturas positivas menor que o uso da tobramicina tanto na conjuntiva como na pálpebra (Tabelas 13,14 e 15).

Analisando as bactérias isoladas na conjuntiva e pálpebra, notamos que tanto no grupo submetido à cirurgia de catarata quanto no grupo submetido à cirurgia refrativa, o microrganismo mais freqüente foi o Staphylococcus coagulase negativa, seguido pelo Corynebacterium $s p$ e em terceiro lugar o Staphylococcus aureus. Isto foi verificado em todas as colheitas de conjuntiva e pálpebra, mesmo com o uso ou não de

\begin{tabular}{|c|c|c|}
\hline $\begin{array}{c}\text { Sem profilaxia } \\
3 \text { dias antes da } \\
\text { cirurgia }\end{array}$ & $\begin{array}{c}\text { Com profilaxia } \\
1 \text { semana após } \\
\text { cirurgia }\end{array}$ & $\begin{array}{l}\text { Após profilaxia } \\
15 \text { dias sem } \\
\text { antibiótico }\end{array}$ \\
\hline \multicolumn{3}{|l|}{ Conjuntiva } \\
\hline$\%$ do total & 3,3 & 40,0 \\
\hline \% de redução & 93,3 & 20,0 \\
\hline z calc & $2,68^{*}$ & 0,00 \\
\hline \multicolumn{3}{|l|}{ Pálpebra } \\
\hline$\%$ do total & 36,7 & 70,0 \\
\hline \% de redução & 52,2 & 8,7 \\
\hline z calc & $2,14^{*}$ & 1,24 \\
\hline
\end{tabular}

antibióticos, não houve mudança na ordem de freqüência das bactérias. Analisando-se a identificação de Staphylococcus coagulase negativa isolados no estudo, o mais freqüentemente encontrado foi o Staphylococcus epidermidis, seguido pelo $S$. hominis 1 e 2, S. saprophyticus, S. xylosus 2, S. haemolyticus 1 e $S$. warneri, nos grupos que realizaram cirurgia de catarata e cirurgia refrativa.

\section{DISCUSSÃO}

O uso de antibióticos profiláticos na cirurgia oftalmológica é um assunto polêmico, pois se discute a validade de, na administração de antibiótico tópico, modificarmos a microbiota conjuntival. Sabe-se também que a infecção intra-ocular 


\begin{tabular}{|c|c|c|c|}
\hline \multicolumn{4}{|c|}{$\begin{array}{l}\text { Tabela 11. Porcentagem de culturas positivas e porcentagem de } \\
\text { redução das culturas em olhos }(n=30) \text { submetidos à cirurgia re- } \\
\text { frativa, tratados profilaticamente com Tobramicina tópica, de acordo } \\
\text { com presença ou não de profilaxia concomitante e o local da colheita } \\
\text { (conjuntiva ou pálpebra) e resultados da estatística, São Paulo, } 2000\end{array}$} \\
\hline & $\begin{array}{l}\text { Sem profilaxia } \\
\text { No centro } \\
\text { cirúrgico }\end{array}$ & $\begin{array}{c}\text { Com profilaxia } \\
1 \text { semana após } \\
\text { cirurgia }\end{array}$ & $\begin{array}{c}\text { Após profilaxia } \\
15 \text { dias sem } \\
\text { antibiótico }\end{array}$ \\
\hline \multicolumn{4}{|l|}{ Conjuntiva } \\
\hline$\%$ do total & 40,0 & 6,7 & 50,0 \\
\hline \% de redução & & 83,3 & $-25,0$ \\
\hline z calc & & $3,03^{*}$ & 0,78 \\
\hline \multicolumn{4}{|l|}{ Pálpebra } \\
\hline$\%$ do total & 90,0 & 46,7 & 83,3 \\
\hline \% de redução & & 48,1 & 7,4 \\
\hline z calc & & $2,51^{*}$ & 0,00 \\
\hline
\end{tabular}

Tabela 12. Porcentagem de redução nas culturas positivas após antibioticoterapia profilática tópica de acordo com presença ou não de profilaxia concomitante e o local da colheita (conjuntiva ou pálpebra) e a droga utilizada, em olhos $(n=30)$ submetidos à cirurgia refrativa e resultados da estatística, São Paulo, 2000

\begin{tabular}{lcc|} 
& $\begin{array}{c}\text { Com profilaxia } \\
\text { 1 semana após cirurgia }\end{array}$ & $\begin{array}{c}\text { Após profilaxia } \\
\text { 15 dias sem antibiótico }\end{array}$ \\
Conjuntiva & & \\
Lomefloxacina & 93,3 & 20,0 \\
Tobramicina & 83,3 & $-25,0$ \\
z calc & 1,17 & $3,85^{\star}$ \\
Pálpebra & & \\
Lomefloxacina & 52,2 & 8,7 \\
Tobramicina & 48,1 & 7,4 \\
z calc & 0,31 & 0,18 \\
\hline
\end{tabular}

Tabela 13. Porcentagem de culturas e porcentagem de redução das culturas com isolamento de Staphylococcus coagulase negativa em olhos $(n=30)$ submetidos à cirurgia refrativa, tratados profilaticamente com Lomefloxacina tópica, de acordo com presença ou não de profilaxia concomitante e o local da colheita (conjuntiva ou pálpebra) e resultados da estatística, São Paulo, 2000

\begin{tabular}{|lccc|} 
& $\begin{array}{c}\text { Sem profilaxia } \\
\text { 3 dias antes } \\
\text { da cirurgia }\end{array}$ & $\begin{array}{c}\text { Com profilaxia } \\
\text { 1 semana após } \\
\text { cirurgia }\end{array}$ & $\begin{array}{r}\text { Após profilaxia } \\
\text { 15 dias sem } \\
\text { antibiótico }\end{array}$ \\
$\begin{array}{l}\text { Conjuntiva } \\
\text { \% do total } \\
\text { \% de redução }\end{array}$ & 43,3 & 0,0 & 30,0 \\
z calc & & 100,0 & 30,8 \\
$\begin{array}{l}\text { Pálpebra } \\
\text { \% do total }\end{array}$ & $3,02^{*}$ & 0,55 \\
\% de redução & 76,7 & 23,3 & 70,0 \\
z calc & & 69,6 & 8,7 \\
\hline
\end{tabular}

pós-operatória é, em geral, grave, tendo em muitos casos prognóstico reservado.

Os pacientes analisados neste estudo foram pacientes normais, sem qualquer sinal ou alteração anatômica que pudesse levar a uma modificação da microbiota conjuntival.

Este estudo, com o objetivo de detectar as mudanças na
Tabela 14. Porcentagem de culturas e porcentagem de redução das culturas com isolamento de Staphylococcus coagulase negativa em olhos $(n=30)$ submetidos à cirurgia refrativa, tratados profilaticamente com Tobramicina tópica, de acordo com presença ou não de profilaxia concomitante e o local da colheita (conjuntiva ou pálpebra) e resultados da estatística, São Paulo, 2000

\begin{tabular}{lccc|} 
& $\begin{array}{c}\text { Sem profilaxia } \\
\text { 3 dias antes } \\
\text { da cirurgia }\end{array}$ & $\begin{array}{c}\text { Com profilaxia } \\
\text { 1 semana após } \\
\text { cirurgia }\end{array}$ & $\begin{array}{c}\text { Após profilaxia } \\
\text { 15 dias sem } \\
\text { antibiótico }\end{array}$ \\
$\begin{array}{l}\text { Conjuntiva } \\
\text { \% do total }\end{array}$ & 33,3 & 6,7 & 46,7 \\
\% de redução & & 80,0 & $-40,0$ \\
z calc & & $2,45^{\star}$ & 0,78 \\
Pálpebra & & & \\
\% do total & 73,3 & 40,0 & 83,3 \\
\% de redução & & 45,5 & $-13,6$ \\
z calc & & $2,15^{*}$ & 0,33 \\
\hline
\end{tabular}

Tabela 15. Porcentagem de redução nas culturas com isolamento de Staphylococcus coagulase negativa após antibioticoterapia profilática tópica de acordo com presença ou não de profilaxia concomitante e o local da colheita (conjuntiva ou pálpebra) e a droga utilizada, em olhos $(n=30)$ submetidos à cirurgia refrativa e resultados da estatística, São Paulo, 2000

\begin{tabular}{lcc|} 
Conjuntiva & $\begin{array}{c}\text { Com profilaxia } \\
\text { semana após cirurgia }\end{array}$ & $\begin{array}{c}\text { Após profilaxia } \\
\text { 15 dias sem antibiótico }\end{array}$ \\
Lomefloxacina & 100,0 & 30,8 \\
Tobramicina & 80,0 & $-40,0$ \\
z calc & $2,45^{\star}$ & $4,83^{\star}$ \\
Pálpebra & & \\
Lomefloxacina & 69,6 & 8,7 \\
Tobramicina & 45,5 & $-13,6$ \\
z calc & 1,72 & $2,90^{\star}$ \\
\hline
\end{tabular}

microbiota conjuntival e palpebral após a utilização de antibiótico tópico profilático, foi elaborado em grupos de cirurgias: catarata e refrativa por serem estes os procedimentos cirúrgicos mais realizados em oftalmologia na atualidade. Os dois grupos são compostos por populações diferentes em relação à faixa etária e observamos que o número de culturas positivas na conjuntiva e pálpebra do grupo mais jovem foi menor que no grupo mais idoso. Mesmo com esta diferença, foi possível realizar a proposta de analisarmos o efeito da antibioticoterapia tópica na microbiota conjuntival e palpebral.

O número de visitas em cada grupo foi diferente bem como a forma de utilização da profilaxia, pois tentamos nos adequar à rotina pré e pós-operatória destes procedimentos, assim cada grupo recebeu a profilaxia com um antibiótico e analisamos a eficácia deles em reduzir significativamente o número de microrganismos.

Pela análise de nossos resultados, tanto a Lomefloxacina quanto a Tobramicina foram eficazes em diminuir significantemente a microbiota da conjuntiva e da pálpebra enquanto estavam sendo administrados. Notamos que esta diminuição foi mais acentuada na conjuntiva do que na pálpebra, prova- 
velmente porque a administração da droga foi na forma de colírio, ficando por mais tempo em contato com a conjuntiva e fundo de saco do que com a pálpebra. O fato de observarmos grande número de culturas positivas na pálpebra ressalta a necessidade de mantermos a anti-sepsia da pálpebra e conjuntiva no período pré e pós-operatório.

Durante todo o período de utilização dos antibióticos profiláticos, os níveis de redução da microbiota foram semelhantes para os dois antibióticos e após a interrupção, a recuperação da microbiota conjuntival foi mais rápida no grupo que usou a lomefloxacina nos pacientes submetidos à cirurgia de catarata. No grupo submetido à cirurgia refrativa, a recuperação da microbiota foi mais rápida quando utilizamos a tobramicina. A recuperação da microbiota restabelece um equilíbrio no tecido, sendo um fator de proteção para que germes oportunistas e patogênicos não passem a colonizar estes tecidos. A interpretação da recuperação da microbiota conjuntival e palpebral não é objetivo de nosso estudo, porém é uma observação interessante que pode servir de base para futuras investigações. Observamos também que não houve mudança da sensibilidade dos microrganismos quando a microbiota foi recuperada.

Ao analisarmos apenas as culturas com isolamento de Staphylococcus coagulase negativa notamos que, por ser este o microrganismo mais freqüente, os resultados encontrados são semelhantes aos das culturas com todos os microrganismos isolados, tanto no grupo submetido à cirurgia de catarata quanto no grupo submetido à cirurgia refrativa.

Quanto à sensibilidade dos microrganismos isolados aos antibióticos testados, no grupo submetido à cirurgia de catarata e no grupo submetido à cirurgia refrativa observou-se uma maior resistência à tobramicina na maioria das coletas realizadas ao longo do tempo. A lomefloxacina apresentou um número estatisticamente significante menor de bactérias resistentes do que a tobramicina durante o uso da antibioticoterapia tópica profilática.

\section{CONCLUSÃO}

Concluímos, portanto, que a utilização de antibiótico tópico profilático pode reduzir significantemente a presença de bactérias na conjuntiva e pálpebra, não sendo capaz de eliminar totalmente os microrganismos. Quando o microrganismo testado era sensível ao antibiótico usado para profilaxia, o comportamento tanto da lomefloxacina como da tobramicina foi semelhante.

\section{ABSTRACT}

Purpose: To determine the changes in the conjunctival and palpebral flora after topical use of $0.3 \%$ lomefloxacin and
$0.3 \%$ tobramycin eye drops in the preoperative management of patients submitted to cataract and refractive surgery and to assess the chemosensitivity of bacterial isolates from the conjunctiva and eyelid to these antibiotics. Methods: A prospective study of the conjunctival and palpebral flora of patients submitted to cataract or to refractive (PRK or LASIK) surgery was performed. An analysis of the conjunctival and palpebral flora was carried out in patients before surgery without prophylaxis, after surgery during the use of prophylaxis ( $0.3 \%$ lomefloxacin or $0.3 \%$ tobramycin qid) and after discontinuation of the antibiotic. Results: Tobramycin and lomefloxacin reduced the number of positive cultures in specimens from the conjunctiva and eyelid of individuals submitted to cataract and refractive surgery. In both groups, isolated microorganisms displayed a greater resistance to tobramycin. In the group submitted to cataract surgery, patients treated with prophylactic tobramycin showed a slower recovery of the flora after discontinuation of the antibiotic than those treated with lomefloxacin, with the opposite occurring in the group submitted to refractive surgery. Conclusion: Both lomefloxacin and tobramycin were effective in reducing conjunctival and palpebral flora during drug administration. This reduction was more marked in the conjunctiva. Among the various bacterial isolates, there was a greater resistance to tobramycin than to lomefloxacin. The use of antibiotics reduced the incidence of positive cultures more for the conjunctiva than the eyelids.

Keywords: Bacterial eye infections/microbiology; Bacterial eye infections/prevention \& control; Microbial sensitivity tests; Microbial drug resistance; Postoperative complications/prevention \& control; Ophthalmic solutions; Quinolones/therapeutic use; Quinolones/administration \& dosage; Tobramycin/therapeutic use; Tobramycin/administration \& dosage; Comparative study; Prospective studies

\section{AGRADECIMENTOS}

Agradecemos ao Professor Elias Rodrigues de Paiva pela orientação da parte estatística.

\section{REFERÊNCIAS}

1. Kanellopoulos AJ, Dreyer EB. Postoperative infection following current cataract extraction surgery. Int Ophthalmol Clin 1996;36:97-107.

2. Groden LR, Murphy B, Rodnite J, Genvert GI. Lid flora in blepharitis. Córnea 1991;10:50-3.

3. Lima ALH, Santos M, Belfort Jr R, Cabral J, Mós E, Farah M. Microbiota anaeróbica e facultativa da conjuntiva normal de recém-nascidos. Arq Bras Oftalmol 1993;56:138-45.

4. Wadworth NA, Goa KL. Lomefloxacin- a review of its antibacterial activity pharmacokinetic properties and therapeutic use. Drugs 1991;46:1018-60.

5. Mayer H, Ellal J. Lomefloxacin: microbiologic assesment and unique properties. Am J Med 1992;92(Suppl 4A):S58-62. 
6. Pruul H, McDonald PJ. Lomefloxacin-induced modification of the kinetics of growth of gram-negative bacteria and susceptibility to phagocytic killing by human neutrophilis. J Antimicrob Chemother 1990; 25:91-101.

7. Debbia E, Pesce A, Schito GC. In vitro assessment of the postantibiotic effect of lomefloxacin against gram-positive and gram-negative pathogens. Am J Med 992; 92(Suppl 4A):S45-7.

8. Laibson P, Michaud R, Smolin G, Okumoto M, Rosenthal A, Cagle G. A clinical comparison of tobramycin and gentamycin sulfate in the treatment of ocular infections. Am J Ophthalmol 1981;92:836-41.
9. Purnell WD, McPherson SD. An evaluation of tobramycin in experimental corneal ulcers. Am J Ophthalmol 1974;78:318-20.

10. Gwon A. Topical ofloxacin compared with gentamycin in the treatment of external ocular infection. Ofloxacin Study Group. Br J Ophthalmol 1992;76:714-8.

11. Jensen H, Felix C. In vitro antibiotic susceptibilities of ocular isolates in North and South America [commented on Córnea 1998;17:571-2]. Córnea 1998;17:79-87.

\section{$X$ SIMPÓSIO INTERNACIONAL DE CÓRNEA E LENTES DE CONTATO}

\section{5 a 16 de Março de 2002}

\section{Hotel Renaissance - São Paulo - SP}

\section{Promoção: Seminário Oftalmológico da UNICAMP} Informações: JDE Comunicação e Eventos

\section{tels.: ( 11 ) 287-8109 / 287-9378 fax: ( 111 ) 288-8157}

e-mail:jdecomev@uol.com.br 